\title{
Speculation in the Historical Sciences
}

\author{
Derek Turner*
}

\begin{abstract}
Adrian Currie (2018) argues that in historical scientific research, speculation is sometimes justified on pragmatic grounds. Hypotheses that outrun the empirical evidence may still offer indirect epistemic payoff. Although Currie frames the issues in a helpful way, the costs and benefits of speculation may be more of a mixed bag than his discussion would suggest. And his defense of speculation leaves some questions unaddressed, such as whether there is any justification for different levels of tolerance for speculation in different areas of historical science.
\end{abstract}

$$
\begin{gathered}
\text { Keywords } \\
\text { dinosaurs } \bullet \text { historical science } \bullet \text { paleontology } \bullet \text { pragmatic justification } \bullet \text { speculation }
\end{gathered}
$$

Part of an author-meets-critics book symposium on Rock, Bone, and Ruin: An Optimist's Guide to the Historical Sciences (2018, MIT Press) by Adrian Currie, with Adrian Currie, Alison Wylie, Leonard Finkelman, and Joyce C. Havstad.

In Rock, Bone, and Ruin (2018), Adrian Currie offers an account of how historically oriented researchers in paleontology, archaeology, and the geosciences make the most out of their (often) epistemically unlucky circumstances. He argues that there are three things, in particular, that can help scientists gain traction in unlucky circumstances: methodological omnivory, epistemic scaffolding, and "empirically grounded speculation" (309). Together, these three aspects of the practice of historical science help explain its successes. I largely agree with Currie's account of methodological omnivory and epistemic scaffolding, but I want to raise some critical questions about his discussion of speculation.

Currie's defense of speculation makes him stand out among other philosophers working today on issues in historical science, but there is at least one interesting historical antecedent. Way back in 1926, W. M. Davis, a geologist, published a paper in Science that defended the value of "outrageous geological hypotheses." Davis makes much of the fact that today's received wisdom in geology was yesterday's crazy speculation. For example, the now familiar idea that Earth's recent history included ice ages followed by warming spells was once considered fringe, at best. That's partly because it seemed to contradict the widely shared assumption that Earth's history

*Connecticut College, 270 Mohegan Avenue, New London, CT 06320, USA, derek.turner@conncoll.edu

Received 27 March 2019; Accepted 2 April 2019 doi:10.3998/ptpbio.16039257.0011.011 
was characterized by unidirectional gradual cooling $(1926,464)$. So perhaps the history of the earth sciences also speaks in favor of having a relatively high tolerance for speculation. Davis thought that an outrageous speculative hypothesis can sometimes scramble ordinary patterns of thinking, jolt us out of cognitive ruts, and lead us to see familiar things in new ways. He wrote that "we may be pretty sure that the advances yet to be made in geology will at first be regarded as outrages upon the accumulated convictions of to-day" $(1926,464)$.

Currie says that "empirically grounded speculation"-i.e., the good kind of speculationhas two crucial features. First, it "significantly outruns the available evidence" $(2018,289)$. Second, speculation is "empirically grounded" when it "generates epistemic or empirical goods that increase epistemic traction" (289). His central insight here is that sometimes, hypotheses that outrun the available evidence can also serve as useful investigative pulleys and levers. Sometimes it makes sense to use or rely on a claim that outruns the available evidence, because doing so may have indirect epistemic payoff. Thus, some speculative hypotheses are pragmatically "justified on their fruits" (288). A speculative hypothesis can have all sorts of benefits. Even if it ultimately turns out to be wrong, it could be wrong in revealing and helpful ways. Efforts to test a speculative hypothesis could lead to unforeseen refinements in empirical methods. Speculation sometimes "links our little pockets of knowledge to each other," and "unlocks new avenues of investigation" (287). A speculative hypothesis, conjoined with something else we know, could lead to some new conclusion that turns out to be right.

The terminology might be a little confusing-Currie's view is that "empirically grounded" speculation outruns the evidence, and it sounds odd to put it that way-but the underlying philosophical point is an important pragmatic one. It sometimes pays off (albeit indirectly, and in ways that might be hard to predict) to work with hypotheses that outrun the evidence. Excessive fastidiousness and epistemic risk-aversion can even get in the way of investigative success. If scientists conservatively refused to tolerate speculation, they might find it more difficult to gain traction in epistemically unlucky circumstances where the fossil record is gappy and evidential signals are faint.

Optimists sometimes attend selectively to good prospective outcomes, while ignoring the downsides. Currie has a lot of insightful things to say about speculation's benefits, but a high tolerance for speculation could also have costs that need to be considered. The costs and benefits of speculation are more of a mixed bag than Currie's discussion would suggest.

In practice, different subfields within paleontology have different levels of tolerance for speculation. This itself is a fascinating fact about the science that needs to be accounted for. Vertebrate paleontologists and especially dinosaur scientists, who often work with smaller datasets, tend to do a lot more speculating than, say, statistical paleobiologists who seek to identify evolutionary patterns in large samples of (usually marine invertebrate) fossils. Standards differ even in different areas of vertebrate paleontology. For example, I have heard paleontologists complain that it is easier to get a paper on dinosaurs published in a high-profile journal like Science or Nature than it would be if the same research were on fish or salamanders. Journal editors know that dinosaur research is more likely to get media attention. In dinosaur science, speculation sometimes seems to get rewarded and even reinforced in ways that seem to have little connection to any investigative fruits. This happens in part because there is massive public demand for representations of dinosaurs. The dynamics of what Elizabeth Dobson Jones (2019) calls "celebrity science" may also have something to do with the higher tolerance for speculation in fields like dinosaur science and the study of human origins.

The National Museum of Natural History in Washington, DC, is in the middle of a multiyear renovation of its dinosaur hall (Cox 2015). When the exhibits reopen in 2019, the centerpiece will be a mounted display of Tyrannosaurus rex eating Triceratops. T. rex will stand over 
Triceratops, one foot on its victim, with its jaws clamped around the animal's frill (Switek 2015). The design of this exhibit appears to be based on a rather speculative hypothesis about T. rex feeding behavior. In 2012, at the Society for Vertebrate Paleontology meeting, Denver Fowler and colleagues presented a poster describing some suggestive toothmarks in Triceratops frills from the Hell Creek formation in Montana. Their interpretation of those toothmarks is the likely inspiration for the Smithsonian exhibit. This work received considerable media attention at the time, including a short notice in Nature (Kaplan 2012).

Fowler and colleagues (2012) worked with a sample of around one hundred Triceratops specimens. They reported finding various sorts of toothmarks on eleven of those, with some more ambiguous possible toothmarks on seven more. Of those eleven, most were on the skulls. Some smaller number of those are puncture marks that seem attributable to T. rex (the only apex predator found in the same location and strata, though crocodiles are another possible cause). So far, so good. The scientists then tell a somewhat speculative story: "[T] he marks may have been formed as the Tyrannosaurus attempted to move the frill to access the generous neck muscles connected to the skull." And they provided an artistic rendering of the proposed (rather gruesome) T. rex feeding behavior. This led to discussions in the popular media of how T. rex may have begun each meal by ripping the head off of its dinner.

I have not actually been able to find any published, peer-reviewed version of this research on Triceratops frills. Indeed, the abstract for the SVP meeting includes the following fascinating and admirably honest caveat from Fowler:

\section{The real meat of this study will be presented upon publication in a peer-reviewed journal \\ There has been a small amount of press interest in the poster that we presented at SVP 2012. Obviously the subject matter (Tyrannosaurus eating Triceratops) has potential for public interest, and the consequent press coverage is very welcome (thanks!). However, I want to emphasize the difference between promotion of a meeting abstract with that of final published work.}

It's interesting that a major museum would redesign its premier dinosaur exhibit-its main attraction, seen by millions of visitors each year-based on speculative research that hasn't yet made it through the full peer-review process.

Based on publicly available information, it's hard to assess the strength of the evidence of $T$. rex toothmarks in Triceratops frills. But even if (as seems likely) T. rex was indeed responsible for the toothmarks, generalizations about typical T. rex feeding behavior remain speculative given the small sample size. For example, it's entirely possible that T. rex generally avoided eating Triceratops, and that they only did so in times of scarcity. If this were true, it would mean that the Smithsonian exhibit is not representing typical Tyrannosaur feeding behavior, though it does depict a scene that may have occurred now and then.

In one way, this speculation about T. rex feeding behavior is just the opposite of what Davis had in mind when he argued for the value of "outrageous geological hypotheses" in 1926. Note that the Smithsonian's new exhibit is showing us something that's all too familiar: There is a long history of representing T. rex in one-on-one combat with Triceratops, in paleoart and museum exhibits. However, there is no evidence that such combat ever occurred. (Fowler et al. 2012 are clear that their toothmarks could have been made post mortem; see also Farke et al. 2009, who show that combat injuries in Triceratops were mostly caused by conspecifics, not by T. rex.) The Smithsonian installation shows the possible aftermath of a duel that we've already seen

${ }^{1}$ This quotation is from a note that Fowler appended to the 2012 SVP abstract on his web site, http://www. denverfowler.com/publications/Fowler_et_al_2012.htm, last accessed 15 August 2018.

๑ OPEN ACCESS - PTPBIO.ORG 
represented many times. In this respect, it's a bit like a Hollywood sequel: it gives us something slightly new while basically sticking with the conventions of artistic tradition, showing us more of what we enjoyed seeing on earlier occasions. Rather than challenging assumptions, it's giving us a speculative picture that reflects our own biases-we like to watch one-on-one combat (from lightsaber fights, to western duels, to dinosaur fights). So this is a case where the speculation about T. rex feeding behavior does nothing to scramble existing assumptions or nudge us out of cognitive ruts.

Because it's offered in a pragmatic spirit, Currie's defense of speculation can probably absorb these worries. His view can readily handle the possibility that speculation isn't all good. However, this example raises some philosophical questions about speculation in paleontology:

1. What, if anything, might justify the variation in levels of tolerance for speculation in different areas of historical science, including somewhat greater tolerance in dinosaur science?

2. Given the variability in scientific tolerance for speculation, would it be better, in general, if historical scientists were more tolerant of speculation? Should everyone be more like dinosaur scientists?

3. To what extent should we be concerned about cases where museums produce representations of dinosaurs for popular consumption that embody somewhat speculative ideas? Is there some risk of misleading people about the strength of the actual evidence?

4. To what extent should we be concerned about cases where the strongest incentives to speculate are coming from massive public demand for exciting findings about and representations of dinosaurs?

5. Is there some way to safeguard against the possibility that speculation will reinforce existing biases and deepen cognitive ruts?

Taken together, these questions put some pressure on Currie's enthusiastic pro-speculation view. One understandable limitation of his view is that he focuses narrowly in the investigative practice of historical science. The practice of paleontology, however, is not insulated from the practice of producing representations of prehistoric life for public consumption. And that means that any analysis of the costs and benefits of speculation will have to be more complicated than Currie's optimistic discussion might lead one to think. Having said that, his pragmatic framing of the issue sets the table nicely for what could be a much richer exploration of the pros and cons of speculation about rocks, bones, and ruins.

\section{Acknowledgments}

Thanks to Adrian Currie, Leonard Finkelman, Joyce Havstad, Alison Wylie, as well as audience members at the SPSP meeting in Ghent, Belgium, 2018, for helpful feedback.

\section{Literature cited}

Cox, J. W. 2015. "Nation's T. rex Stands Upright for the First Time in 65 Million Years-and He's Scary." The Washington Post (1 October, 2015). https://www.washingtonpost.com/local/ nations- $\mathrm{t}$-rex-stands-upright-for-the-first-time-in-65-million-years--and-hes-scary/2015/10/ 01/9f843fe0-6727-11e5-9223-70cb36460919_story.html. Retrieved 15 August, 2018. 
Currie, A. 2018. Rock, Bone, and Ruin: An Optimist's Guide to the Historical Sciences. Cambridge, MA: MIT Press.

Davis, W. M. 1926. “The Value of Outrageous Geological Hypotheses," Science 63 (1636): 463-468.

Farke, A. A., E. D. S. Wolff, and D. H. Tanke. 2009. “Evidence of Combat in Triceratops.” PloS One 4 (1): e4252.

Fowler, D. W., J. B. Scannella, M. G. Goodwin, and J. R. Horner. 2012. "How to Eat a Triceratops: Large Sample of Toothmarks Provides New Insight Into the Feeding Behavior of Tyrannosaurus." Journal of Vertebrate Paleontology 32 (5, abstracts volume): 96.

Jones, E. D. 2019. "Ancient Genetics to Ancient Genomics: Celebrity and Credibility in Data-Driven Practice." Biology and Philosophy 34: 27. doi:10.1007/s10539-019-9675-1

Kaplan, M. 2012. "How to Eat a Triceratops," Nature (24 October 2012). doi:10.1038/nature.2012.11650

Switek, B. 2015. "When T. rex Meets Triceratops in the New Dino Hall, It Will Be a Violent Affair." Smithsonian (1 October 2015). https://www.smithsonianmag.com/smithsonian-institution/ new-dino-hall-it-gets-violent-when-tyrannosaurus-rex-meets-triceratops-180956793/. Retrieved 15 August, 2018.

(C) 2019 Author(s)

This is an open-access article distributed under the terms of the Creative Commons Attribution 4.0 International license, which permits anyone to download, copy, distribute, display, or adapt the text without asking for permission, provided that the creator(s) are given full credit.

ISSN 2475-3025 